\title{
Angiosarcoma of the liver in Great Britain in proximity to vinyl chloride sites
}

\author{
Paul Elliott, Immo Kleinschmidt
}

\begin{abstract}
Objectives-To study the incidence of angiosarcoma of the liver in England and Wales 1979-86 and Scotland 1975-87. To investigate whether any non-occupational neighbourhood cases occurred near a vinyl chloride site.

Methods-This is a geographical study of incident cases among the general population of Great Britain. Diagnosis of angiosarcoma of the liver was based mainly on the national cancer registry, the world register of cases among vinyl chloride workers, and the register of cases (including histological review) maintained by the Health and Safety Executive. Proximity $(<10 \mathrm{~km})$ of residence to a vinyl chloride site was based on postcode of address at the time of diagnosis.
\end{abstract}

Results-55 cases were ascribed to angiosarcoma of the liver in England and Wales with a further six cases in Scotland (annual incidence in Great Britain from all sources of around 1.4 cases per 10 million population). There were two cases with documented exposure to Thorotrast, and 10 cases among vinyl chloride workers. There were no vinyl chloride sites in Scotland. Among the 25 cases in England and Wales with histological diagnosis after review by a panel of pathologists, only 15 were confirmed as angiosarcoma, and one of the two Scottish cases after histological review was also confirmed. Overall, 11 cases ascribed to angiosarcoma were resident within $10 \mathrm{~km}$ of a vinyl chloride site; nine were vinyl chloride workers, one further case on histological review was not considered to have been correctly diagnosed as angiosarcoma, and the remaining case, confirmed as angiosarcoma, was employed at a vinyl chloride factory during the late 1950 s, although not as a vinyl chloride worker.

Conclusion-The incidence of angiosarcoma of the liver in Great Britain remains extremely rare. The one confirmed case in a non-vinyl chloride worker within 10 $\mathrm{km}$ of a site must nevertheless be presumed to have been exposed to vinyl chloride in the workplace. In the period of study, there were no confirmed non-occupationally exposed cases of angiosarcoma among residents living near a vinyl chloride site in Great Britain.

(Occup Environ Med 1997;54:14-18)
Keywords: vinyl chloride; angiosarcoma; liver

Angiosarcoma of the liver is an extremely rare, rapidly fatal tumour. An association with occupational exposure to vinyl chloride monomer, used in the manufacture of polyvinyl chloride, was first reported in $1974^{1}$; since then a causal association has been established based on results of human occupational and animal experimental studies. ${ }^{2-6}$ Associations with thorium dioxide (Thorotrast, which until the 1960s was used diagnostically as a radioactive contrast medium) and with arsenic exposure have also been described..$^{7-10}$

Few studies are available on the incidence of angiosarcoma of the liver among the general population (see Doll ${ }^{10}$ for a review). Baxter et al reported findings for Great Britain for 1963-73, later extended to 1977, and included one possible non-occupationally exposed neighbourhood case in the vicinity of a vinyl chloride plant. ${ }^{78}$ In the present study, we describe the incidence of angiosarcoma of the liver in Great Britain for a later period with multiple sources of information to find possible cases. We were especially concerned with cases resident in the vicinity (within $10 \mathrm{~km}$ ) of a plant that either handled vinyl chloride or used it for manufacturing. For those cases, we examined whether there was any evidence of occupational exposure to vinyl chloride, Thorotrast, or arsenic, and so whether or not any non-occupational neighbourhood cases had occurred.

\section{Subjects and methods}

Information on cases ascribed to angiosarcoma of the liver in Great Britain was sought from five sources (fig 1). Firstly, all cancer registrations coded to 155.0 (primary liver cancer) with histological code 9120 (angiosarcoma) were retrieved from the database of the Small Area Health Statistics Unit. ${ }^{11} 12$ As histological coding for cancer registrations was not introduced until 1979 with the 9th revision of the international classification of disease (ICD-9), data for England and Wales refer to the period 1979-86 (the last year available at the time of study). In Scotland, cancer registrations before 1979 have been recoded to ICD-9, and so data were available for more years (1975-87). The registration details of cases in England and Wales were checked by the former Office of Population Censuses and Surveys (OPCS), and for Scotland by the Information and Statistics Division of the Scottish Health Service. 
Figure 1 Sources of cases of angiosarcoma of the liver.

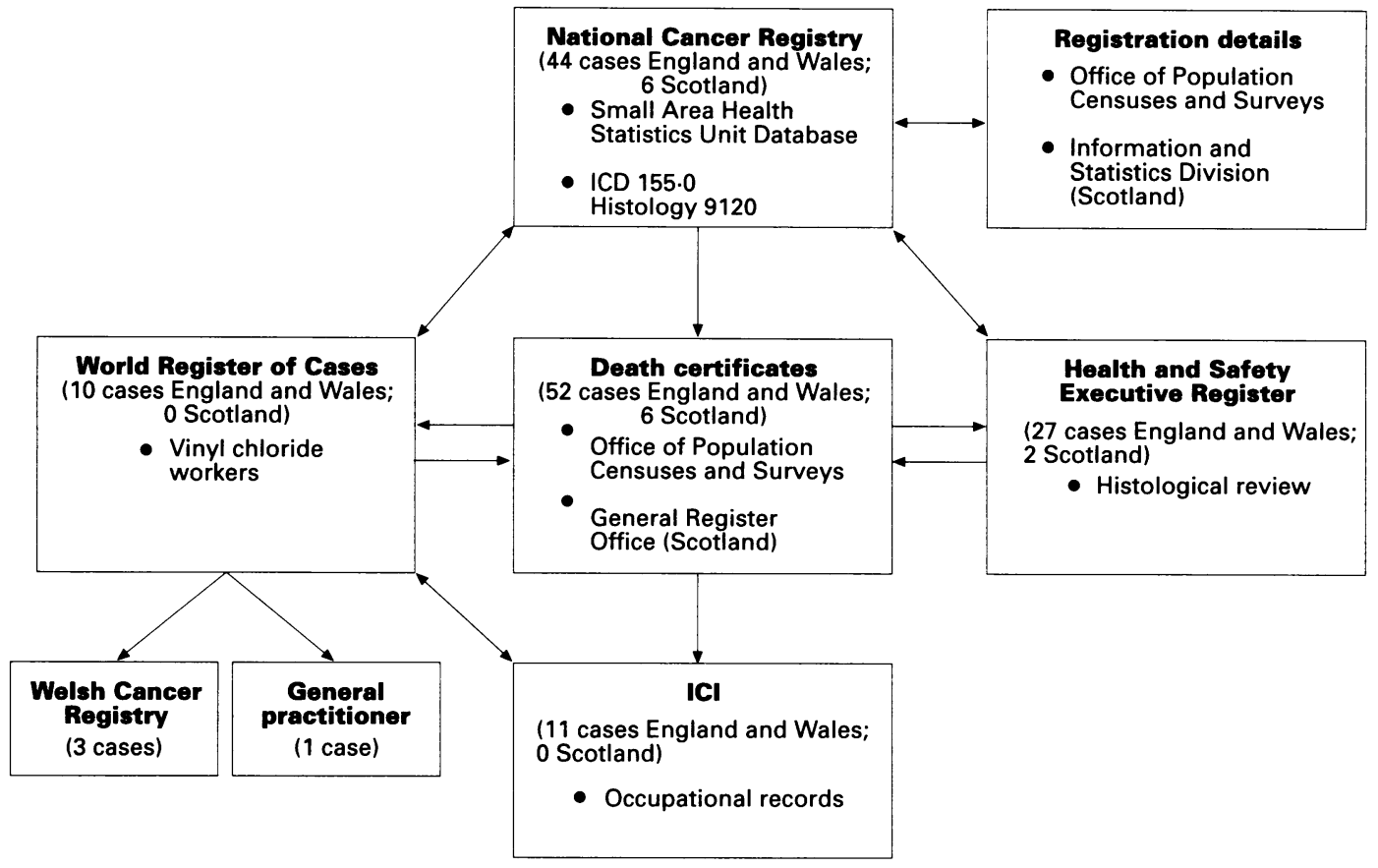

Secondly, copies of death certificates for the incident cases were sought from OPCS for cases in England and Wales and from the General Register Office (Scotland), and both primary and secondary causes of death were ascertained. The death certificates were also examined for mention of occupational exposure to vinyl chloride or industrial disease, and for exposure to Thorotrast or arsenic.

Thirdly, as a further check on cases, the non-confidential parts of the death certificates, including name, sex, address, date of birth, and date of death were abstracted. Extracts from a random sample of death certificates with primary liver cancer as underlying cause of death were included as controls. These were then sent to the Health and Safety Executive for checking against its register of cases, set up in 1974. The register includes histological review by a panel of pathologists of cases identified on the death certificate in Great Britain as angiosarcoma, as well as others identified from published case reports or notes from hospital pathologists or others. ${ }^{7}$ Also, the register was checked for cases presenting with a diagnosis of angiosarcoma of the liver during the period of study that were missing from our lists, and details were sent to us (R Elliott, personal communication). Copies of death certificates (and controls) were also sought for those cases.

Fourthly, extracts of the death certificates for both cases and controls were sent to ICI Chemicals and Polymers to be checked against the occupational records. ICI has responsibility for both its own and former British Petroleum factories, which together contributed around $90 \%$ of workers (J Osman, personal communication) to the Health and Safety Executive's Employment Medical Advisory Service study of mortality among all vinyl chloride workers in Great Britain. ${ }^{413}$

Lastly, the United Kingdom entries on the World Register ${ }^{14}$ of cases were scrutinised and the details compared with those on the data- base of the Small Area Health Statistics Unit. Comparison was made of sex, date of birth, date of death, age at diagnosis, and name of factory. We were also able to use the initials of the case (included on the world register) as names were available to us through the death certificates. Information on cases identified from the world register but not traced through the other sources was sought from the Welsh Cancer Registry (three cases) and, where necessary, through the local general practitioner (one case). Copies of death certificates (and controls) not otherwise obtained were retrieved and extracts sent for checking to the other information sources already described.

Information on the 12 vinyl chloride sites in Great Britain was obtained from the Department of the Environment (S Coster, personal communication), to include dates of operation, map grid references, and details of whether vinyl chloride was made, polymerised, used, or stored (fig 2). None of these sites was in Scotland. Cases were located by postcode of residence at the time of the diagnosis of cancer, or death, and the distance from the nearest vinyl chloride site was computed. Postcodes for three of the cases in England and Wales were missing from the database and were obtained from the death certificate or from OPCS.

\section{Results}

ENGLAND AND WALES

One duplicate registration was found. Overall, there were 55 cases ascribed to angiosarcoma in England and Wales 1979-86 (53 adults and two children (both female, ages 5 and 6)). Among adults, there were 37 men (ages 36-83 years; median 57 years) and 16 women (ages 25-80; median 59). Numbers of cases a year ranged from three (1986) to 10 (1983) (fig 3).

As expected, there was considerable overlap between sources (table 1). Of the total of 55 cases, 44 were identified on the national can- 


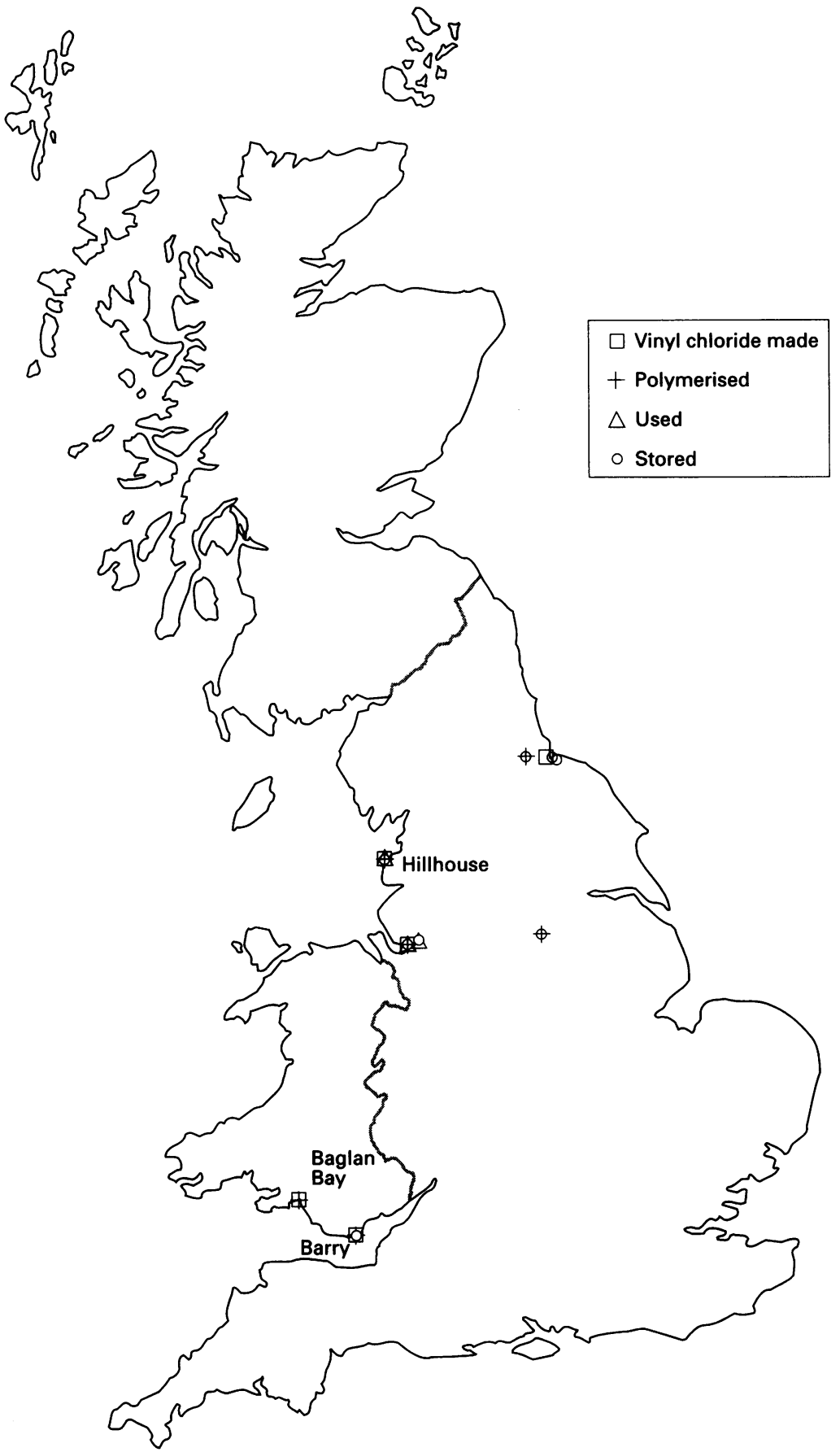

Figure 2 Vinyl chloride sites in Great Britain.

cer registry. Copies of death certificates were obtained for 52 cases including 41 of the 44 cases that were found on the National Cancer Registry, and all 11 identified by ICI from its

Figure 3 Numbers of cases of angiosarcoma of the liver by year, England and Wales, 1979-86. occupational records, 10 of which also appeared on the World Register for 1979-86. Of these 10 world register cases, only six were also found on the National Cancer Registry, although three further cases were on the Welsh Registry but had not been entered on to the national registry. Nine of the 10 World Register cases were also included among the 27 cases on the Health and Safety Executive register. Seventeen of these 27 cases were on the National Registry, and a further threethat is, nine minus six (table 1, last column) were on the World Register but not on the National Registry. The remaining seven cases were identified only from the Health and Safety Executive register itself. Two of the 27 cases on the register had pathology recorded as "not yet known"; on panel review of the remaining 25 cases, 15 had the diagnosis of angiosarcoma confirmed (including the case known to ICI that was not on the world register: see discussion of table 2 later), and 10 were considered not to be angiosarcoma.

Death certificate diagnoses of haemangiosarcoma or angiosarcoma of the liver were recorded in 36 of the 52 cases for which a copy of the certificate was obtained, including one as a secondary cause of death, and two that mentioned Thorotrast exposure. Also, three cases were recorded as either haemangioendothelioma (one), haemangioendothelial sarcoma (one), or malignant haemangioma (one), considered to be synonymous with a death certificate diagnosis of angiosarcoma. ${ }^{7}$ One case with a death certificate diagnosis of haemangiocarcinoma and one with carcinomatosis were diagnosed as true angiosarcoma according to the Health and Safety Executive review panel, although the death certificate obtained for the case of carcinomatosis was possibly a mismatch as identifying details included on the register were scanty. One occupational case on the World Register had a death certificate diagnosis of hepatic fibrosis (and industrial disease was noted); the review panel considered that the diagnosis was not angiosarcoma (table 2). Death certificate diagnoses for the remaining 10 cases included hepatic tumour (one); hepatoma (two); chronic liver disease (one); angiocarcinoma of the liver (one); ischaemic heart disease and haemangioma of the liver (one); and four nonhepatic diseases, bronchogenic carcinoma (one), sarcoma of the kidney (one), melanoma (one), and carcinomatosis (one). None of the death certificates mentioned exposure to arsenic.

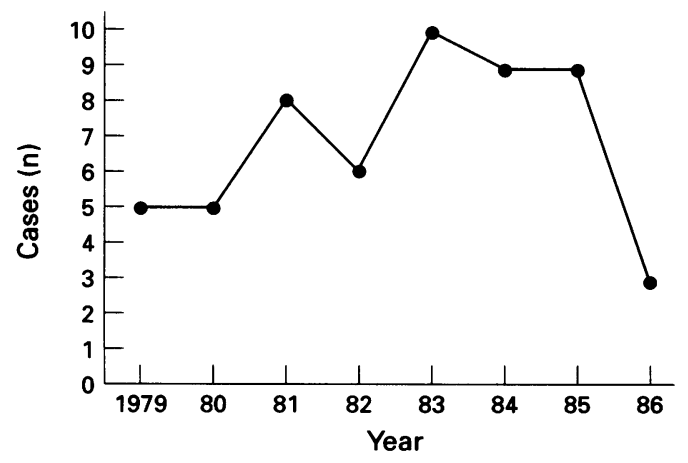

Table 2 lists all 11 cases in England and Wales ascribed to angiosarcoma during 1979-86 that were resident within $10 \mathrm{~km}$ of a vinyl chloride site (fig 2) at the time of the diagnosis of cancer. Nine of these cases were known vinyl chloride workers included on the World Register (the 10th World Register case was resident $11 \mathrm{~km}$ from the Barry factory). Eight were also on the Health and Safety Executive register, four with confirmed angiosarcoma, three were considered not to have angiosarcoma, and for one histology was recorded as not yet known. 
Table 1 Number of cases by information source, England and Wales, 1979-86 (55 cases in total)

\begin{tabular}{llllcc}
\hline & $\begin{array}{l}\text { National } \\
\text { Registry }\end{array}$ & $\begin{array}{l}\text { Death } \\
\text { certificate }\end{array}$ & HSE & ICI & $\begin{array}{l}\text { World } \\
\text { Register }\end{array}$ \\
\hline National Registry & 44 & 41 & 17 & 6 & $6 \ddagger$ \\
Death certificate & - & $52 \S$ & 27 & 11 & 10 \\
HSE & - & - & 27 & 10 & 9 \\
ICI & - & - & - & 11 & 10 \\
World Register & - & - & - & - & 10 \\
\hline
\end{tabular}

^Primary liver cancer (ICD 155.0) and histology code 9120 .

tHealth and Safety Executive Register.

¥Three further cases on the World Register were also on the Welsh Cancer Registry (two coded as angiosarcoma of liver) but not on the National Registry.

Of the 55 cases in total, death certificates were untraceable for three cases on the National Registry.

The total from each source is given along the diagonal; the rows and columns describe the overlap between sources. carcinomatosis of the liver (primary site undetermined), and diffuse poorly differentiated malignant lymphoma. None of the Scottish cases was known to ICI, or appeared on the World Register, and none mentioned Thorotrast or exposure to arsenic.

\section{Discussion}

We found 55 cases ascribed to angiosarcoma of the liver in England and Wales, 1979-86 and a further six cases in Scotland, 1975-87 giving a reported annual incidence in Great Britain of around 1.4 cases per 10 million population. These cases were based mainly on cancer registration, the world register of cases and the register maintained by the Health and Safety Executive. There were two cases with documented exposure to Thorotrast, none with exposure to arsenic, and 10 cases occurred in vinyl chloride workers. The incidence of around seven cases a year from all sources is similar to that reported for Great Britain during an earlier period (up to 1977), ${ }^{8}$ although the sources of cases were different. In the previous study, ${ }^{78}$ the primary source was death certificates supplemented by case reports and notifications from hospital pathologists and others. Among the 25 (of 27) cases in England and Wales included here from the Health and Safety Executive register with histological review by a panel of pathologists, only 15 were confirmed as angiosarcoma, a higher proportion than in the previous study ${ }^{7}$ but based on a smaller percentage of the total number of cases. Only two of the six Scottish cases were included on the Health and Safety Executive register; one was confirmed as angiosarcoma on histological review.

We were particularly concerned in the present study to detect possible neighbourhood (non-occupational) cases in view of the theoretical risk of possible low level environmental hazard related to the operation of vinyl chloride sites, although the historical exposure to high concentrations of vinyl chloride in the workplace has been greatly reduced in recent years. ${ }^{10}$ In the previous study in Great Britain, one possible neighbourhood case was described, with no known occupational expo-

Table 2 Angiosarcoma (ASL) cases * within $10 \mathrm{~km}$ of a vinyl chloride (VCM) site, England and Wales 1979-86

\begin{tabular}{|c|c|c|c|c|c|c|c|c|}
\hline Site & $\begin{array}{l}\text { Year } \\
\text { of diagnosis }\end{array}$ & Age & Sex & $\begin{array}{l}\text { Distance from } \\
\text { site }(\mathrm{km})\end{array}$ & $\begin{array}{l}\text { Exposure } \\
\text { history }\end{array}$ & $\begin{array}{l}\text { World } \\
\text { Register }\end{array}$ & $\begin{array}{l}\text { Death } \\
\text { certificate }\end{array}$ & $\begin{array}{l}\text { HSE panel } \\
\text { diagnosis }\end{array}$ \\
\hline $\begin{array}{l}\text { Hillhouse } \\
\text { Barry } \\
\text { Hillhouse } \\
\text { Barry } \\
\text { Barry } \\
\text { Barry } \\
\text { Barry } \\
\text { Barry } \\
\text { Baglan Bay } \\
\text { Barry } \\
\text { Barry }\end{array}$ & $\begin{array}{l}85 \\
79 \\
79 \\
80 \\
80 \\
81 \\
85 \\
86 \\
79 \\
83 \\
84\end{array}$ & $\begin{array}{l}48 \\
65 \\
58 \\
48 \\
60 \\
57 \\
57 \\
37 \\
63 \\
42 \\
37\end{array}$ & $\begin{array}{l}M \\
M \\
M \\
M \\
M \\
M \\
M \\
M \\
M \\
F \\
M\end{array}$ & $\begin{array}{l}1 \\
2 \\
3 \\
3 \\
4 \\
5 \\
5 \\
5 \\
6 \\
6 \\
8\end{array}$ & $\begin{array}{l}\text { VCM } \\
\text { VCM } \\
\text { VCM } \\
\text { VCM } \\
\text { VCM } \\
\text { VCM } \\
\text { VCM } \\
\text { VCM } \\
\dagger \\
\ddagger \\
\text { VCM }\end{array}$ & $\begin{array}{l}\text { Yes } \\
\text { Yes } \\
\text { Yes } \\
\text { Yes } \\
\text { Yes } \\
\text { Yes } \\
\text { Yes } \\
\text { Yes } \\
\text { No } \\
\text { No } \\
\text { Yes }\end{array}$ & $\begin{array}{l}\text { ASL/Ind } \\
\text { ASL/Ind } \\
\text { ASL/Ind } \\
\text { ASL/Ind } \\
\text { S } \\
\text { ASL/Ind } \\
\text { ASL/Ind } \\
\text { ASL/Ind } \\
\text { ASL } \\
\text { ASL/Ind } \\
\text { ASL }\end{array}$ & $\begin{array}{l}\text { Not ASL } \\
\text { ASL } \\
\text { Not ASL } \\
\pi \\
\text { Not ASL } \\
\text { ASL } \\
\text { ASL } \\
\overline{\text { Not ASL }} \\
\text { ASL } \\
\text { ASL }\end{array}$ \\
\hline
\end{tabular}

‡One further occupationally exposed case resident at $11 \mathrm{~km}$.

†Exposure status not known according to HSE register. Case not identified as a worker on ICI records. $\ddagger$ Recorded as having VCM expost

VCM according to ICI records.
SHepatic fibrosis and industrial disease.

\Hepatic fibrosis and industrial disease.

THistology not yet known according to HSE register. Histology confirmed as angiosarcoma according to World Register.
$-=$ Not on HSE register; HSE = Health and Safety Executive; Ind = industrial disease recorded on death certificate. 
sure but residence for six years within half a mile of a plant manufacturing polyvinyl chloride. ${ }^{7}$ In the United States, five non-occupational cases were reported living within a mile of a vinyl chloride plant. ${ }^{9}$ Of these six possible neighbourhood cases, Doll (1988) later excluded two (including the British case) on the grounds that the periods between possible exposure and disease were too short, but concluded that the four other cases were strongly suggestive of an effect of environmental pollution around those plants.

We found 11 cases ascribed to angiosarcoma within $10 \mathrm{~km}$ of a vinyl chloride site, eight near the Barry factory, one near Baglan Bay (both in South Wales), and two near Hillhouse (Lancashire). Nine of these cases were vinyl chloride workers, four with confirmed angiosarcoma by review of the panel. Of the two remaining cases, one diagnosis on review was thought not to have been angiosarcoma. The final case with confirmed angiosarcoma, although not a vinyl chloride worker, nevertheless worked at the Barry factory during the late 1950 s before the hazards associated with vinyl chloride exposure were known, and before effective containment measures were in place. This case was classed as having an industrial disease; it must be presumed that she had been exposed to vinyl chloride in the workplace. We therefore conclude that, in the period of study, there were no confirmed nonoccupationally exposed cases of angiosarcoma among residents living near a vinyl chloride site in Great Britain.

The Small Area Health Statistics Unit is funded by grants from the Department of Health, Department of the Environment, Health and Safety Executive, Scottish Office Home and Health Department, Welsh Office, and Northern Ireland Department of Health and Social Services. We thank the former Office of Population, Censuses and Surveys (OPCS) and the Information and Statistics Division of the Scottish Health Service, who made the postcoded cancer data available to us, and for checking registration details of individual cases. We thank OPCS and the General Register Office (Scotland) for providing copies of death certificates. We are grateful for the prforts of the individual cancer registries that submit data to the prational cancer registration scheme, and especially data to the nationals cancer registration scheme, and especially the Welsh Cancer Registry for checking cases. We thank $S$ Coster (Department of the Environment), R Elliott, J Osman (Health and Safety Executive), G Paddle, J Paterson, and J Tomenson (ICI Chemicals and Polymers). The views expressed in this publication are those of the authors and not necessarily those of the funding departments.

1 Creech JL, Johnson MN. Angiosarcoma of liver in the manufacture of polyvinyl chloride. $\mathcal{F}$ Occup Med 1974, 16:150-1.

2 Viola PL, Bigotti A, Caputo A. Oncogenic response of rat skin, lungs, and bones to vinyl chloride. Cancer Res 1971; 31:516-9.

3 Maltoni C, Ciliberti A, Gianni L, Chieco P. Vinyl chloride carcinogenesis: current results and perspectives. Med Lav 1974:65:421-44.

4 Jones RD, Smith DN, Thomas PG. A mortality study of vinyl chloride monomer workers employed in the United Kingdom in 1940.

5 Theriault G, Allard P. Cancer mortality of a group of Canadian workers exposed to vinyl chloride monomer. $\mathcal{f}$ Occup Med 1981;23:671-6.

6 Wu W, Steenland K, Brown D, Wells V, Jones J, Schulte P, Halperin W. Cohort and case-control analyses of workers exposed to vinyl chloride: an update. $\mathcal{F}$ Occup Med 1989; 31:518-23.

7 Baxter PJ, Anthony PP, MacSween RNM, Scheuer PJ. Angiosarcoma of the liver in Great Britain, 1963-73. BMF 1977;2:919-21.

8 Baxter PJ, Anthony PP, MacSween RNM, Scheuer PJ. Angiosarcoma of the liver: annual occurrence and aetiology in Great Britain. Br f Ind Med 1980;37:213-21.

9 Brady J, Liberatore F, Harper P, Greenwald P, Burnett W, Davies TN, et al. Angiosarcoma of the liver: an epidemioDavies TN, et al. Angiosarcoma of the liver: an epid

10 Doll $R$. Effects of exposure to vinyl chloride: an assessment of the evidence. Scand $\mathcal{F}$ Work Environ Health 1988;14: 61-78.

11 Elliott P, Westlake AJ, Hills $M$, Kleinschmidt I, Rodrigues L, McGale P, Marshall K, Rose G. The Small Area Health Statistics Unit: a national facility for investigating health around point sources of environmental pollution in the United Kingdom. I Epidemiol Community Health 1992;46:345-9.

12 Elliott P, Kleinschmidt I, Westlake AJ. Use of routine data in studies of point sources of environmental pollution. In: studies of point sources of environmental pollution. In: Elliott P, Cuzick J, English D, Stern R, eds. Geographical and environmental epidemiology: methods for small-area
ies. Oxford: Oxford University Press, 1992:106-14.

13 Fox AJ, Collier PF. Mortality experience of workers exposed to vinyl chloride monomer in the manufacture of polyvinyl chloride in Great Britain. Br f Ind Med 1977; 34:1-10.

14 Forman D, Bennett B, Stafford J, Doll R. Exposure to vinyl chloride and angiosarcoma of the liver: a report of the register of cases. Br $\mathcal{F}$ Ind Med 1985;42:750-3. 